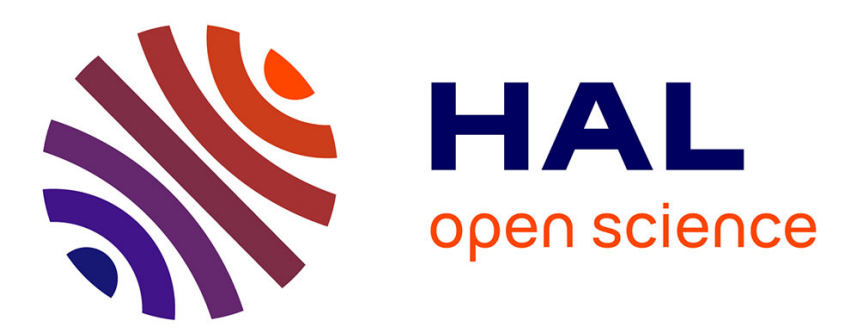

\title{
High current density via direct electron transfer by the halophilic anode respiring bacterium Geoalkalibacter subterraneus
}

Alessandro Carmona Martinez, Mélanie Pierra, Eric Trably, Nicolas Bernet

\section{To cite this version:}

Alessandro Carmona Martinez, Mélanie Pierra, Eric Trably, Nicolas Bernet. High current density via direct electron transfer by the halophilic anode respiring bacterium Geoalkalibacter subterraneus. Physical Chemistry Chemical Physics, 2013, 15 (45), pp.19699 - 19707. 10.1039/c3cp54045f . hal$01131065 \mathrm{v} 1$

\section{HAL Id: hal-01131065 \\ https://hal.science/hal-01131065v1}

Submitted on 12 Mar 2015 (v1), last revised 26 Nov 2015 (v2)

HAL is a multi-disciplinary open access archive for the deposit and dissemination of scientific research documents, whether they are published or not. The documents may come from teaching and research institutions in France or abroad, or from public or private research centers.
L'archive ouverte pluridisciplinaire HAL, est destinée au dépôt et à la diffusion de documents scientifiques de niveau recherche, publiés ou non, émanant des établissements d'enseignement et de recherche français ou étrangers, des laboratoires publics ou privés. 
Carmona Martinez, A., Pierra, M., Trably, E., and Bernet, N. 2013. Physical Chemistry Chemical Physics, 15(45):19699 - 19707. http://dx.doi.org/10.1039/c3cp54045f

1 High current density via direct electron transfer by the halophilic anode respiring 2 bacterium Geoalkalibacter subterraneus

3 Alessandro A. Carmona-Martínez*, Mélanie Pierra, Eric Trably and Nicolas Bernet

4 INRA, UR0050, Laboratoire de Biotechnologie de l'Environnement, Avenue des Etangs,

5 Narbonne, F-11100, France

6 Keywords: Geoalkalibacter subterraneus, Bioelectrochemical systems, Cyclic voltammetry,

7 Confocal Laser Scanning Microscopy, Direct electron transfer

8 *author of correspondence; phone: +33 (0) 4684251 62; fax: +33 (0)4 684251 60, email to:

9 alessandro.carmona@ supagro.inra.fr

10 Abstract

11 In this study the characterization of Geoalkalibacter subterraneus is presented, a novel 12 halophilic anode respiring bacteria (ARB) previously selected and identified in a 13 potentiostically controlled bioelectrochemical system (BES) inoculated with sediments from a 14 salt plant. Pure culture electroactive biofilms of Glk. subterraneus were grown during 15 chronoamperometric batch experiments at a graphite electrode poised at +200 mV (vs. SCE) 16 with $10 \mathrm{mM}$ acetate as electron donor. These biofilms exhibited the highest current density $17\left(4.68 \pm 0.54 \mathrm{~A} / \mathrm{m}^{2}\right)$ reported on a planar material with a pure culture under saline conditions $18(3.5 \% \mathrm{NaCl})$. To investigate possible anodic electron transfer (ET) mechanisms, cyclic voltammetry $(\mathrm{CV})$ of mature visible apparent reddish biofilms was performed under bioelectrocatalytic substrate consumption (turnover) and in absence of substrate (nonturnover). CV evidenced a well defined typical sigmoidal shape and a pair of clear redox couples under turnover and non-turnover conditions, respectively. Moreover, the calculation of their formal potentials indicated the presence of a common ET mechanism present in both $\mathrm{CV}$ conditions between $-427.6 \pm 0.5\left(E_{\mathrm{f}, 2}\right)$ and $-364.8 \pm 4.5 \mathrm{mV}\left(E_{\mathrm{f}, 3}\right)$. Confocal laser scanning microscopy inspection showed a biofilm structure composed of several layers of metabolically active bacteria that spread all over the electrode material within a biofilm up to $76 \pm 7 \mu \mathrm{m}$ thick. Such value, high for the thickness normally reported in the literature for pure culture electroactive bacteria justifies further investigations. Taken together, these results suggest that Glk. subterraneus performs a direct ET mechanism in contact with the electrode

30 material. Furthermore, direct current generation from saline wastewaters significantly expands 31 the application of BESs. 


\section{Introduction}

33 Bioelectrochemical systems (BESs) are a group of technologies derived from the bidirectional electron transfer (ET) interactions between microorganisms and electrode materials ${ }^{1}$. More specifically: 1) the harvest of electrons from the oxidation of a substrate and their further transfer to an electrode (e.g., for the direct production of electricity ${ }^{2}$ ) and 2) the uptake of electrons from the electrode material to reduce a substrate for the production of valuable industrial products such as hydrogen gas $^{3}$, sodium hydroxide or acetate ${ }^{4}$. Up to now, two main microbial ET mechanisms have been extensively described: direct electron transfer (DET) and mediated electron transfer (MET). Whereas in DET bacteria need to be in direct contact with the electrode material to release/accept electrons via c-type cytochromes ${ }^{5}$, in MET bacteria are capable of releasing/accepting electrons via self produced redox mediator molecules such as flavins ${ }^{6}$ or phenazines ${ }^{7}$ (among others ${ }^{8-11}$ ). Although microbial ET mechanisms in BESs have been extensively studied in two model bacteria families such as Geobacteraceae and Shewanaellaceae ${ }^{1}$, there are many other bacteria capable of donating/accepting electrons to/from an electrode (see Table S1).

While members of the Geobacteraceae family are capable of performing a DET mechanism, with significant current densities (up to $9 \mathrm{~A} / \mathrm{m}^{2}$ ) ${ }^{12}$ and forming thick biofilms (about $50 \mathrm{um}^{13-}$ ${ }^{18}$ ) in freshwater environments, Shewanaellaceae is capable of performing both DET and MET mechanisms. Interestingly, Shewanaellaceae produces very low current densities ${ }^{19}$, likely due to their limitation to form thin-monolayer biofilms on the electrode surface ${ }^{20,21}$. Although their ET mechanisms are extensively understood, there is still a great interest to identify and characterize other bacteria capable of forming electroactive biofilms and producing significant current densities since they can aid to comprehend more precisely how ET occurs through different microbial species ${ }^{22,23}$. Furthermore, direct current generation from saline wastewaters as the ones produced in the sea-food, petroleum and leather industries could significantly broad the application of BESs.

For the characterization of electroactive bacteria diverse techniques are available. These techniques target practically all type of parameters, from architecture to electrochemistry of biofilms $^{24}$. Here, the novel halophilic anode respiring bacterium (ARB) Geoalkalibacter subterraneus (henceforth, Glk. subterraneus) is characterized. Glk. subterraneus was previously selected and identified in a potentiostically controlled BES inoculated with sediments from a salt plant ${ }^{25}$. An electrochemical as well as a microscopic approach was employed. Chronoamperometry was used to evaluate Glk. subterraneus's maximum current 
density production with intermittent measurements of its ET mechanism by cyclic voltammetry and confocal laser scanning microscopy to analyze biofilm electrode coverage and thickness.

\section{Results and discussion}

2.1 Bioelectrochemical biofilm formation of Geoalkalibacter subterraneus and generation of high current density under saline conditions

Fig. 1 shows a representative chronoamperometric (CA) biofilm growth of Glk. subterraneus on a graphite planar electrode at an applied potential of $+200 \mathrm{mV}$ (vs. SCE) with $10 \mathrm{mM}$ sodium acetate as the electron donor. For all CA biofilm growth experiments, strict anoxic conditions were procured as described in the Experimental section and routinely tested by gas chromatographic analysis since Glk. subterraneus preferentially grows under these conditions $^{26}$.

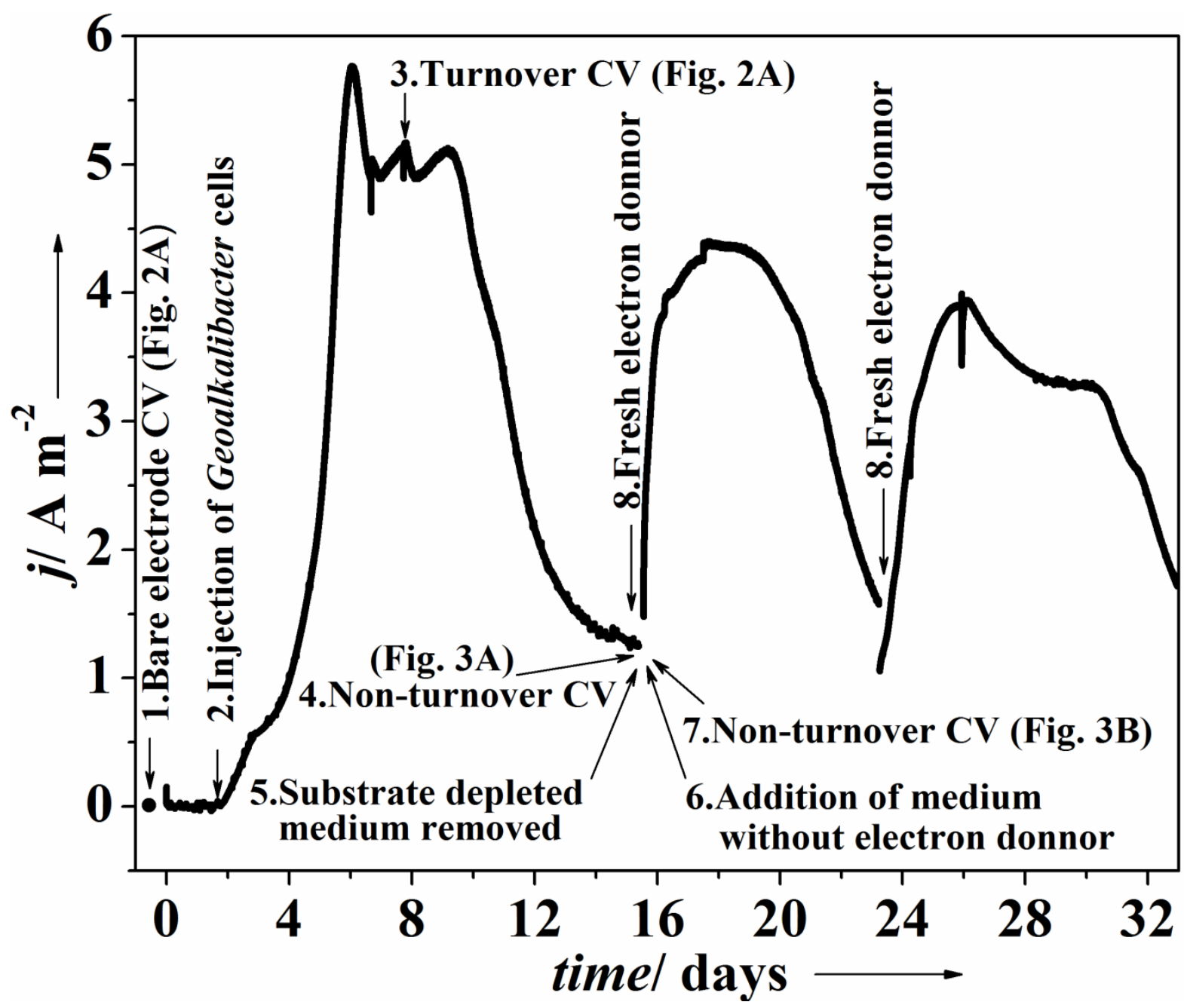

Fig. 1 Representative chronoamperometric fed-batch cycles of Geoalkalibacter subterraneus biofilms grown on graphite planar electrodes $\left(15 \mathrm{~cm}^{2}\right)$; applied potential: $+200 \mathrm{mV}$ vs. SCE $(\mathrm{KCl} 3.0 \mathrm{M})$. 
81 As denoted in Fig. 1, approximately after $24 \mathrm{~h}$ of poising the working electrode immersed in 82 the growth medium, the electrochemical cell was inoculated and it took around 24 more hours for biofilm growth to begin. This was illustrated as an exponential-like current production trend, characteristic of ARB able to produce high currents and thick biofilms ${ }^{27-29}$ (see Table S1). Fig. 1 shows that at day six of incubation, the current density peaked a maximum value $\left(j_{\max }\right)$ of about $5.7 \mathrm{~A} / \mathrm{m}^{2}$. This value establishes the highest current density produced by an ARB pure culture under saline conditions $(3.5 \% \mathrm{NaCl})^{30}$.

When comparing $j_{\max }$ by pure culture biofilms of $G l k$, our results are consistent with previous observations in our group for biofilms enriched with Geoalkalibacter in potentiostically controlled BESs inoculated with sediments from a salt plant $\left(j_{\max }: 4.5 \text { to } 8.5 \mathrm{~A} / \mathrm{m}^{2}\right)^{31}$. Furthermore, our results corroborate as well those of a recent publication by Miceli et al., $(2012)^{32}$ showing Geoalkalibacter dominated biofilms derived from environmental anaerobic samples $\left(j_{\max }: 4.2\right.$ and $\left.8.9 \mathrm{~A} / \mathrm{m}^{2}\right)$. Similarly, Badalamenti et al. $(2013)^{30}$ reported the electrochemical performance of Glk. subterraneus grown on graphite rod electrodes under lower saline conditions $(1.7 \% \mathrm{NaCl})$. They showed also a significant high $j_{\max }\left(3.3 \mathrm{~A} / \mathrm{m}^{2}\right)$ but lower than the one reported here $\left(5.7 \mathrm{~A} / \mathrm{m}^{2}\right)$. One reason why current densities reported here were higher, could be the discrepancy between their and our experimental procedures (see Table S2); e.g.: higher concentration of salt (therefore increasing the conductivity of the electrolyte solution ${ }^{33}$ ), more positive applied potential (hence increasing biofilm formation ${ }^{19}$ ) and distance between working and counter electrodes due to BES architecture ${ }^{34}$. Nevertheless, in our experiments a lower concentration of electron donor (10 $\mathrm{mM}$ sodium acetate) generated higher current densities. A finding not totally consistent with literature data, since it has been extensively demonstrated that the current density augments by increasing the concentration of substrate until saturation kinetics ${ }^{35,36}$.

After the maximum current density was reached, a period of a stable current production was observed at $4.68 \pm 0.54 \mathrm{~A} / \mathrm{m}^{2}$ (when both reproducible replicates are considered for the calculation, see Fig. S1). In between, CA was stopped and turnover CV was performed as

108 indicated in the Experimental section. Around day nine, CA showed a sudden current 109 decrease due to substrate exhaustion as confirmed at the end of the cycle by metabolite 110 analysis. The conversion of substrate into current as coulombic efficiency (CE) was assessed 111 by considering the ratio of electrons actually obtained from the substrate and the amount of 112 electrons theoretically available ${ }^{2}$. Here, in semi-batch half-cell experiments, CE exceeded $113100 \%(114 \pm 14)$. This was likely due to oxidation of hydrogen produced at the cathode ${ }^{37}$ 
114 since a significant percentage (oxidizable by Glk. subterraneus ${ }^{26}$ ) was detected in the gas 115 phase of our experiments (e.g., the gas composition during CA at the maximum of current 116 production was $\mathrm{CO}_{2} 16.6 \%, \mathrm{H}_{2} 82.2 \%, \mathrm{O}_{2} 1.05 \%$ and $\mathrm{CH}_{4} 0.34 \%$ ). The focus of this study 117 was the characterization of Glk. subterraneus in terms of current output, electron transfer and 118 biofilm formation and not maximizing CE as would be typical for applied BESs such as 119 microbial fuel cells ${ }^{2}$ or microbial electrolysis cells ${ }^{3}$.

120 In several studies where electroactive bacteria are characterized as a pure culture, it has been 121 usually found that in further batch CA cycles performed by media replenishment, the current 122 recovers or exceeds its previous value ${ }^{38-44}$. As seen in Fig. 1, the current density did not 123 recover its previous value after the substrate depleted media was replenished at the end of the 124 first and second CA semi-batch cycles. On the other side, the immediate production of current 125 can be considered a proof of bacteria's ability to convert the supplied substrate into current instead of using it for biosynthesis ${ }^{45}$. Therefore, this points out a possible direct electron transfer (DET) mechanism ${ }^{23}$.

128 A similar phenomenon where current density does not recover its previous value was also observed elsewhere ${ }^{22,30,46-52}$. A possible explanation could be that the presence of a substance (or substances) produced in the previous CA cycle is required to achieve previous similar 131 performance, hence hindering the biofilm to produce as much current density as in the 132 previous CA cycle.

\section{3}

134

135

136

137

138

139

140

141

142

143

144 145

\subsubsection{Comparison of Geoalkalibacter subterraneus and Geobacter sulfurreducens in terms}

\section{of chronoamperometric current density production}

To conduct an accurate comparison of the performance of Glk. subterraneus, parallel electrochemical experiments were carried out with the extensively well characterized ${ }^{12,53-60}$ model bacteria Geobacter sulfurreducens (hereafter, Gb. sulfurreducens). Gb. sulfurreducens was employed here as an appropriate reference of an ARB in terms of $j_{\max }$ obtained during CA experiments, analysis of its ET mechanism with cyclic voltammetry (CV) and biofilm examination with the use of confocal laser scanning microscopy (CLSM) under similar experimental conditions; i.e.: identical half-cell architecture and components, temperature, $\mathrm{pH}$ and applied potential.

Under our experimental conditions, Gb. sulfurreducens was able to produce a higher $j_{\max }$ $\left(11.60 \pm 2.21 \mathrm{~A} / \mathrm{m}^{2}\right)$ than the one obtained with Glk. subterraneus (see Table S1 and Fig. S1). Gb. sulfurreducens biofilms obtained here produced results which corroborate previous 
146 findings obtained by others with this model bacterium ${ }^{12,28,29,51,61}$. This confirms that: 1) our

147 experimental methods are well standardized procedures comparable to the ones reported in 148 the current literature and that 2) Gb. sulfurreducens is the ARB producing the highest current 149 densities in a fresh water environment. In addition, a plausible reason why Gb. sulfurreducens 150 biofilms outperformed Glk. subterraneus in terms of $j_{\max }$ is related to the diversified ET 151 mechanism found in Gb. sulfurreducens. This is illustrated by the presence of several redox 152 couples in CV and higher biofilm electrode coverage as per CLSM (see below).

\subsection{Turnover CV analysis of Geoalkalibacter subterraneus in the presence of substrate}

154 To analyze the extracellular electron transfer mechanism occurring in Glk. subterraneus, CV 155 was performed during three different conditions as described in the Experimental section. 156 Representative CVs for both conditions are shown in Fig. 2 (turnover) and Fig. 3 (non157 turnover). As proof that the turnover and non-turnover CV signals are due to a biofilm formed 158 at the electrode surface, a control $\mathrm{CV}$ of the bare surface electrode immersed in growth 159 medium is included for comparison (dotted line in Fig. 2A and in Fig. 3A). The negative control CV showed no appreciable signals.

161 Fig. 2A shows a representative turnover CV illustrating a sigmoidal shape typically found in ARB able to produce high currents and thick biofilms like Geobacter sulfurreducens PCA $^{12}$, Rhodopseudomonas palustris DX-1 $1^{40}$, Thermincola ferriacetica DSMZ $14005^{22}$ and more recently Geoalkalibacter ferrihydriticus DSM $17813^{30}$. Badalamenti et al. ${ }^{30}$ reported the CV characterization of Glk. subterraneus biofilms but only under turnover conditions and showing a sigmoidal shape. The present observations of turnover CV analysis corroborate the findings of Badalamenti et $a l^{30}$. However, the existing differences are very likely due to experimental procedures. When calculating the respective first derivative of the turnover $\mathrm{CV}$ of Glk. subterraneus, under our experimental turnover conditions, two different inflection points are revealed (Fig. 2B). A first inflection point with a formal potential $\left(E_{\mathrm{f}, 1}\right)$ at $-446.5 \pm$

$171 \quad 1.2$ and a second clearly prominent inflection point $E_{\mathrm{f}, 3}$ at $-364.8 \pm 4.5 \mathrm{mV}$ (vs. SCE), a 172 potential commonly ascribed to DET-proteins (see Fig S2). Likewise, multiple inflection 173 points in the first derivative (here defined as $E_{\mathrm{f}, 1}$ ) have been reported elsewhere for other 174 electroactive bacteria such as Gb. sulfurreducens ${ }^{27,51,55,61}$ and T. ferriacetica ${ }^{41}$. Nevertheless, 175 it is not completely clear how these non prominent "additional" inflection points (such as $E_{\mathrm{f}, 1}$ ) are involved in the overall ET mechanism ${ }^{51}$. 


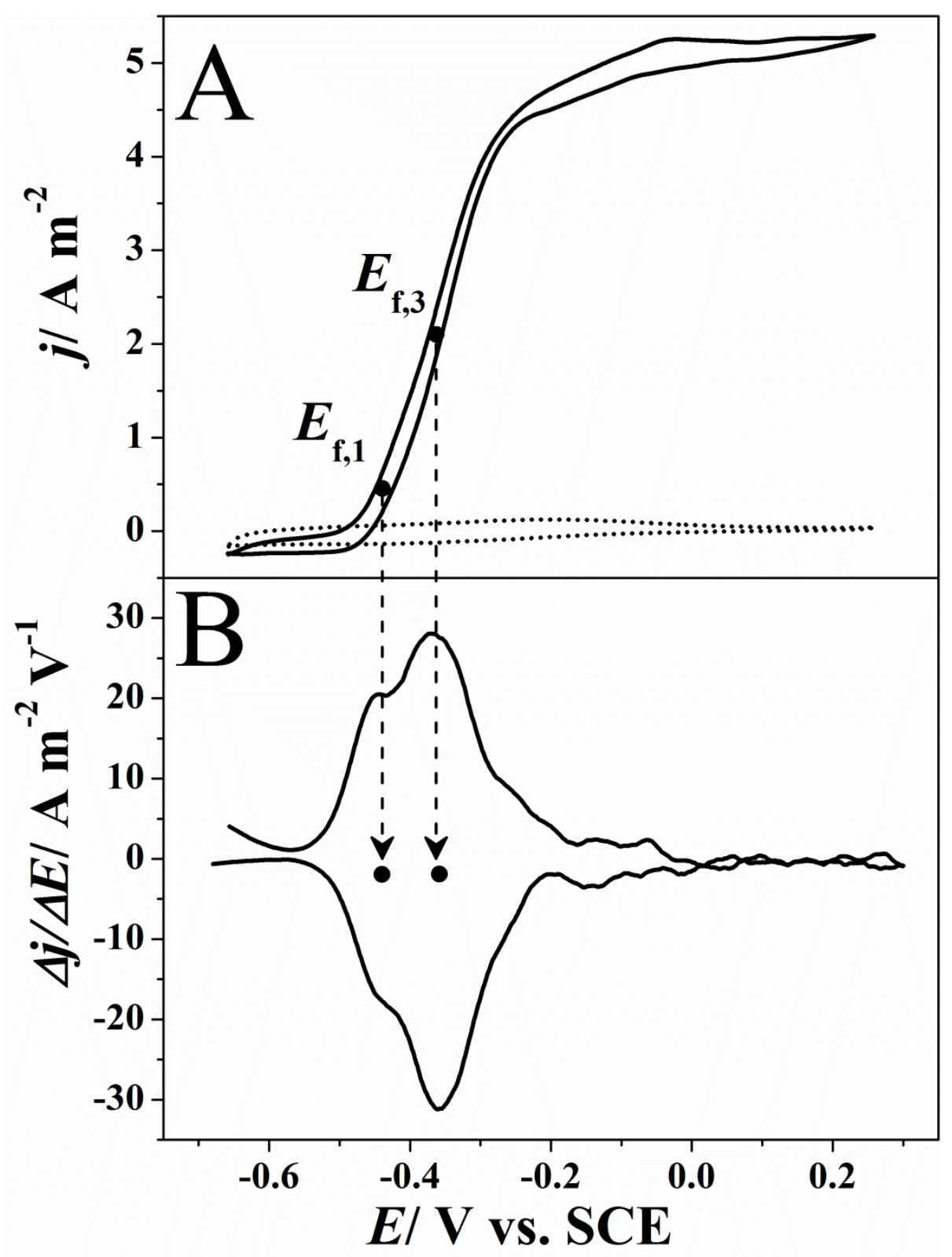

178 Fig. 2 A) Representative turnover cyclic voltammogram of a Geoalkalibacter subterraneus 179 biofilm (continuous line) and B) respective first derivative curve. As well in A), dotted line 180 shows bare electrode CV performed before chronoamperometric biofilm growth.

181 When examining the turnover CV signal, it is clear that the CV shape shown here resembled 182 the one seen for bacteria capable of performing a DET mechanism via outer membrane 183 cytochromes (OMCs). Nevertheless, there is still no conclusive evidence whether OMCs are 184 responsible for a DET mechanism in the electroactive biofilms of Glk. subterraneus. 185 Moreover, the prominent inflection point potentials found here were very similar to the 186 potential found for DET (see Fig. S2). As shown in Fig. S2, bacteria able to perform a DET 187 mechanism presented an inflection point in a very broad potential window that ranged from - 
500 to $-300 \mathrm{mV}$ vs. SCE. However these differences could be attributed to the particular growth conditions (e.g., $\mathrm{pH}$, temperature, substrate, salt concentration, among others).

\subsubsection{Turnover CV comparison of Geoalkalibacter subterraneus and Geobacter} sulfurreducens biofilms

192 Further evidence of a DET mechanism performed by Glk. subterraneus was provided by a

193 comparative analysis conducted while performing electrochemical experiments to grow 194 electroactive biofilms of Gb. sulfurreducens (see Fig. S1). Fig. S3 shows an exemplary 195 turnover CV of a Glk. subterraneus biofilm compared to a turnover CV of a $G b$. 196 sulfurreducens biofilm. As expected, Gb. sulfurreducens illustrated the typical sigmoidal 197 shape under turnover conditions obtained by others ${ }^{12,27,51,55,61}$ and its first derivative showed 198 as well two inflection points included in the potential window of $E_{\mathrm{f}, 1}$ and $E_{\mathrm{f}, 3}$ (see Fig. S3). 199 This provides additional information on the ability of Glk. subterraneus to perform a DET mechanism and could indicate a similar ET process as in the case of Gb. sulfurreducens.

2.3 Non-turnover CV analysis of Geoalkalibacter subterraneus in the absence of substrate

Fig. 3 shows exemplary non-turnover CVs of a Glk. subterraneus biofilm. Fig. 3A shows a substrate-depleted CV when substrate was totally consumed (as per metabolite analysis) during $\mathrm{CA}$ cycle and Fig. 3B shows a substrate-deprived CV when the substrate depleted medium was replenished for fresh medium with no electron donor.

208 Both non-turnover CVs in Fig. 3A and B depict a very similar voltammogram shape. 209 Additionally, both CVs possess two apparent redox couples with formal potentials $E_{\mathrm{f}, 2}$ and $210 E_{\mathrm{f}, 4}$. However, the substrate-depleted CV in Fig. 3A exhibits a catalytic behaviour with a 211 limiting current of about $2 \mathrm{~A} / \mathrm{m}^{2}$. When compared to Fig. 3B, the limiting current masks the 212 two redox couples that were clearly observed when CV was performed in total absence of 213 electron donor (under substrate deprived non-turnover CV). The catalytic behaviour observed 214 in Fig. 3A could be due to the presence of a substance (or substances) produced during CA. 215 Interestingly, the observed catalytic current of $2 \mathrm{~A} / \mathrm{m}^{2}$ during non-turnover $\mathrm{CV}$ in Fig. 3A was 216 in agreement with the current density observed at the end of the first CA cycle shown in Fig. 1 217 (residual current of about $1.3 \mathrm{~A} / \mathrm{m}^{2}$ ). 


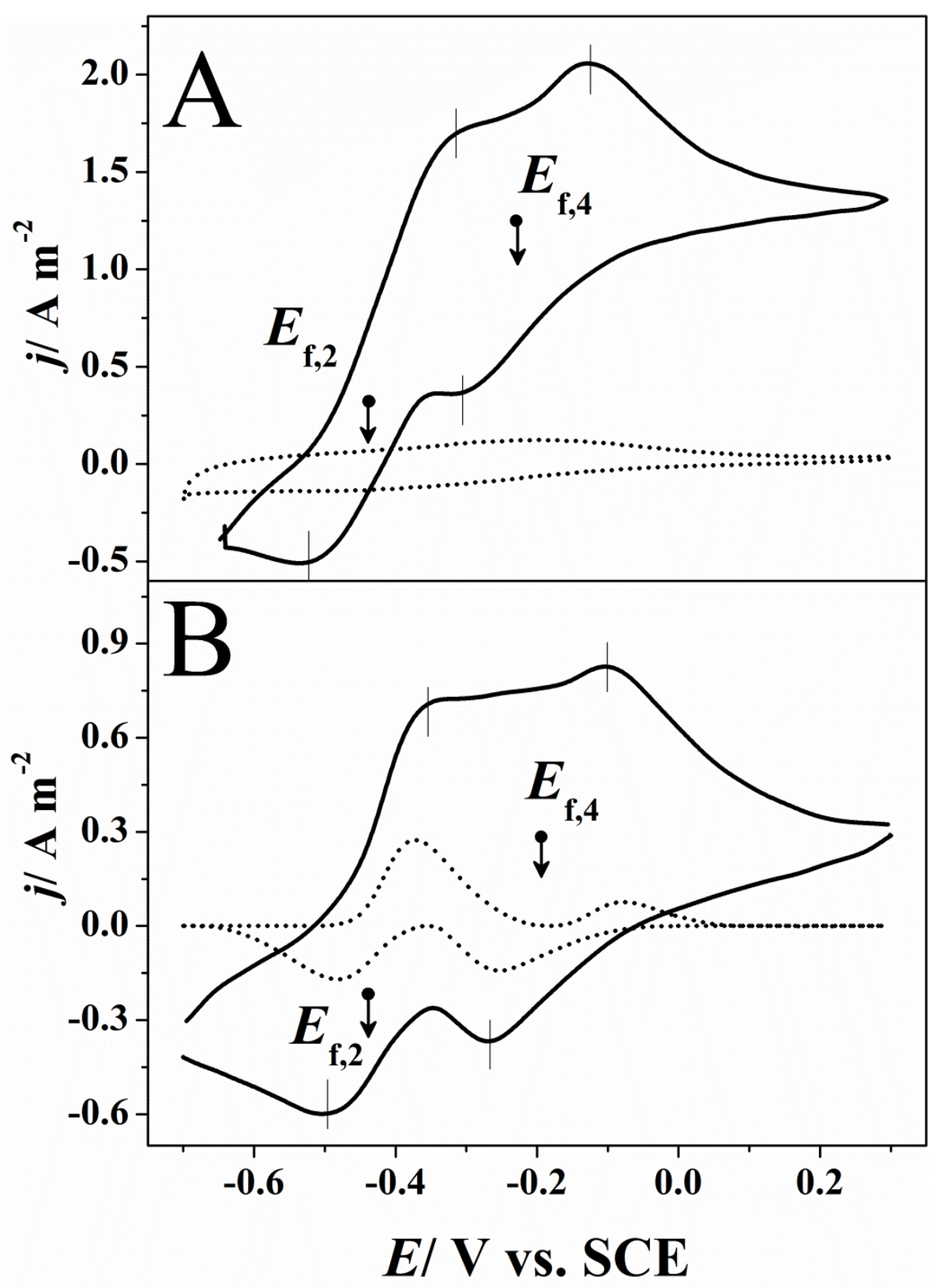

220 Fig. 3 A) Representative cyclic voltammogram of Geoalkalibacter subterraneus biofilm u 221 substrate depleted conditions (continuous line) and cyclic voltammogram of bare electrode 222 (dotted line); B) substrate deprived non-turnover cyclic voltammogram (dotted line provides 223 the respective SOAS $^{62}$ base-line subtracted curve).

224 Fig. 3B shows the SOAS ${ }^{62}$ base-line subtracted curve (dotted line) of the substrate deprived 225 non-turnover CV (see Experimental section). The subtracted CV clearly depicts the position 226 of two redox couples with formal potentials $E_{\mathrm{f}, 2}$ and $E_{\mathrm{f}, 4}$ at $-427.6 \pm 0.5$ and $-165.5 \pm 2.6 \mathrm{mV}$ 227 vs. SCE, respectively. The value of $E_{\mathrm{f}, 2}$ was close to both formal potentials derived from first 228 derivatives of CV under turnover conditions (see Fig. 2). This could indicate that the redox 229 couple detected at $E_{\mathrm{f}, 2}$ was responsible for the bioelectrocatalytic electron transfer. 
230 Nevertheless, the lack of an electrochemical characterization of the OMCs of Glk. 231 subterraneus prohibits an a priori assignment of $E_{\mathrm{f}, 2}$ to a certain type of protein (or multiple 232 proteins) responsible for the suggested DET mechanism.

2.3.1 Non-turnover CV comparison of Geoalkalibacter subterraneus and Geobacter sulfurreducens biofilms

235 Further data supporting a putative DET by Glk. subterraneus comes from the comparison of

236 its non-turnover CV with the one obtained with Gb. sulfurreducens biofilms. Although non237 turnover CVs of Glk. subterraneus (with two redox systems) and Gb. sulfurreducens (with 238 four redox couples previously observed ${ }^{27,51}$ ) differed significantly (see Fig. S4), the value of 239 Glk. subterraneus's formal potential $E_{\mathrm{f}, 2}$ was close to Gb. sulfurreducens's $E_{\mathrm{f}, G b 2}$. This 240 suggests a common DET mechanism in both bacteria. Based on this experimental data and on 241 previous studies of $G b$. sulfurreducens that propose a DET via OMCs ${ }^{63}$, we suggest to ascribe 242 the formal potential $E_{\mathrm{f}, 2}$ found here for Glk. subterraneus to a DET very likely via an OMC. 243 Future research should therefore concentrate on the investigation of the OMC (or OMCs) 244 involved in the DET mechanism of Glk. subterraneus.

245 The proper assignation of $E_{\mathrm{f}, 4}$ to a respective ET mechanism (Fig. 3B) was not a 246 straightforward task. Some authors previously suggested a possible explanation based on the $247 \mathrm{CV}$ observed for Gb. sulfurreducens biofilms ${ }^{27,51}$. Here we propose to extrapolate such 248 explanation derived from the comparison of Fig. 2B and 3B to our results. From these figures 249 one can see that $E_{\mathrm{f}, 1}, E_{\mathrm{f}, 2}$ and $E_{\mathrm{f}, 3}$ share a very similar value. Therefore, it can be hypothesized 250 that these redox processes contributed to the bioelectrocatalytic anodic electron transfer. On 251 the other hand, since $E_{\mathrm{f}, 4}$ does not have a formal potential match in turnover conditions, it 252 appears to have no contribution in the overall ET mechanism.

\subsection{Imaging of Geoalkalibacter subterraneus biofilm surface coverage and thickness} using confocal laser scanning microscopy

255 In order to study how Glk. subterraneus (and Gb. sulfurreducens for comparison) attached to 256 the electrode surface, confocal laser scanning microscopy (CLSM) was used to conduct a 257 qualitative (with LAS AF and Volocity ${ }^{\circledR}$ ) description and a quantitative (with PHLIP) biofilm 258 analysis as described in the Experimental section. In this course, it has to be noticed that this 259 is the first CLSM description of Glk. subterraneus electroactive biofilms. CLSM was used 260 first of all, for its advantage over Scanning electron microscopy for quantitatively analyzing 261 in depth the layers across the biofilm and hence, allowing the calculation of surface coverage 262 and thickness ${ }^{64}$. Second, CLSM allows a live biofilm to be imaged by avoiding a harsh drying 
procedure that could change its morphology. In our experiments the biofilms were stained

264 with a LIVE/DEAD® kit. Bacterial cells embed in biofilms stained green which could indicate that most of the cells were still metabolically active at the moment of the CLSM analysis ${ }^{17}$. However, since this is the first work reporting the use of this kit with biofilms of Glk. subterraneus, the successful staining of dead cells of this bacterium should be still experimentally tested. The maximum intensity projection of a Glk. subterraneus biofilm is shown in Fig. 4A. This picture confirms a very uniform coverage of the electrode surface as previously observed by visual inspection of a reddish biofilm (see Fig. S5). Additionally, when analyzing the different slices that compose the maximum intensity projection, it is clear that the biofilm was constituted of a stack of several biofilm monolayers (see Fig. S6). From the different orthogonal cross sections made throughout the biofilm, it seems that the biofilm is about $30 \mu \mathrm{m}$ thick (Fig. 4B). However, this idea was later discarded by PHLIP quantitative analysis which showed a biofilm with a thickness value of $76 \pm 7 \mu \mathrm{m}$ as described in the following section. Further 3D reconstruction with Volocity ${ }^{\circledR}$ revealed a very peculiar biofilm structure (see Fig. S7) composed of an undulating structure distributed across the analyzed electrode surface sample probably caused by biofilm overgrown which matches previous observations in Gb. sulfurreducens biofilms ${ }^{17,51}$.

\subsubsection{CLSM comparison of Geoalkalibacter subterraneus and Geobacter sulfurreducens} biofilms

The comparison of Glk. subterraneus and Gb. sulfurreducens CLSM pictures is shown in Fig. S8 and in Table S3. It was observed that Glk. subterraneus produced a lower current density $\left(4.68 \pm 0.54 \mathrm{~A} / \mathrm{m}^{2}\right)$ when it formed a thicker biofilm $(76 \pm 7 \mu \mathrm{m})$ than $G b$. sulfurreducens. Nevertheless, the average electrode coverage value of Gb. sulfurreducens (31 $\pm 16 \%$ ) is higher than the one of Glk. subterraneus $(23 \pm 7 \%)$ and therefore indicating that these differences in biofilm architecture contribute to explain the higher current density by $G b$. sulfurreducens. A similar trend was recently reported by Richter et al. ${ }^{65}$. They studied $G b$. sulfurreducens wild-type and the mutant pilA4, a strain expressing only the short isoform of the PilA preprotein that composes the type IV pili of Gb. sulfurreducens, a protein essential for DET. Therefore, diminishing the ability of the mutant to effectively transfer electrons to insoluble Fe(III) oxides and graphite anodes. Whereas the wild-type of Gb. sulfurreducens produced a higher current density, it showed a thinner biofilm but higher electrode coverage value than the mutant. 
295 One issue that emerges from the thickness observed in Glk. subterraneus is that the value is 296 very high for the values normally reported in the literature for pure culture electroactive 297 bacteria $^{14-18}$. Thus, to be the first CLSM description of this strain, it is advisable and 298 justifiable to further investigate the possible reasons behind the biofilms produced by this 299 electroactive bacterial species.
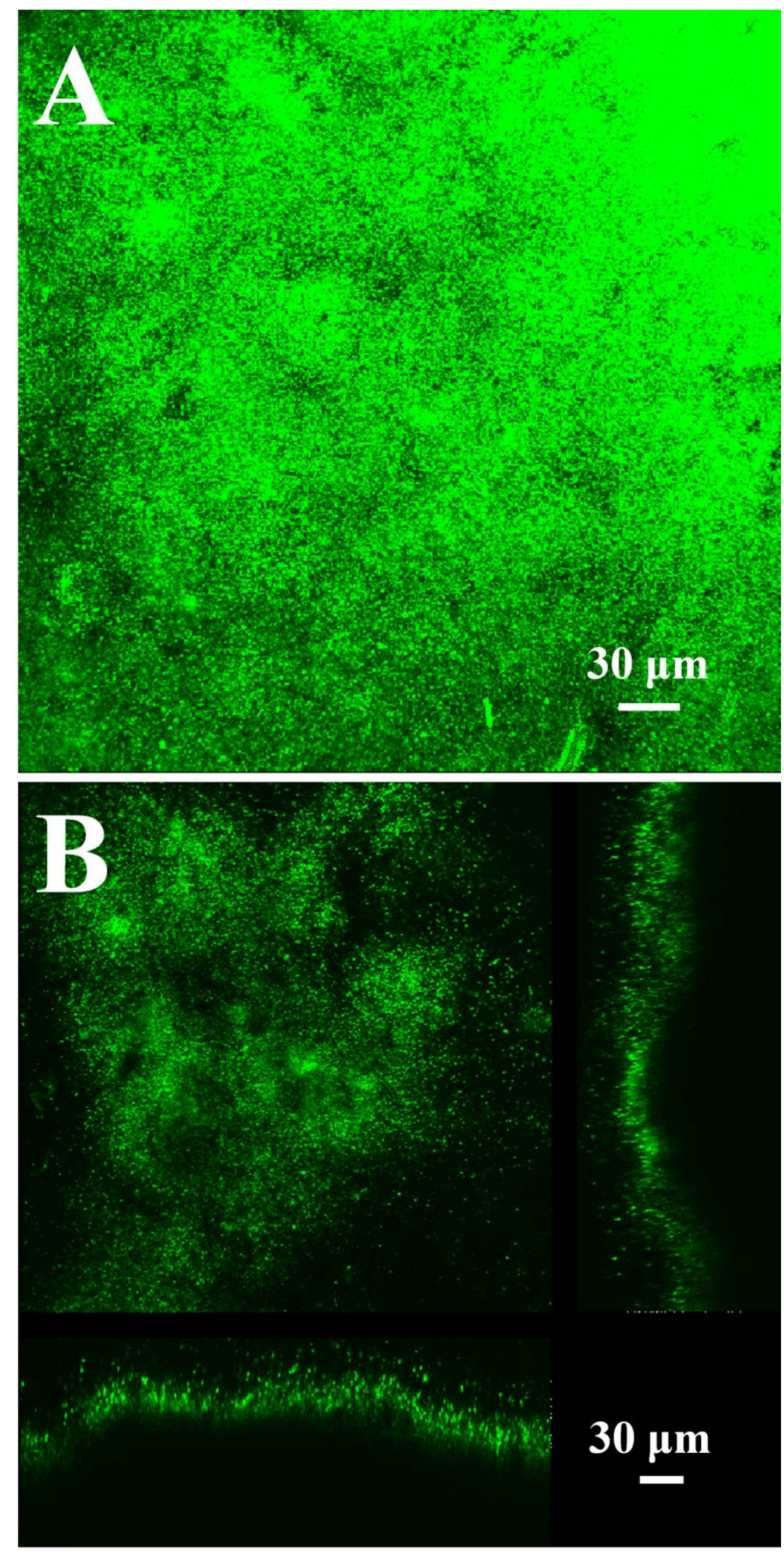
301 Fig. 4 Exemplary confocal laser scanning microscopy of Geoalkalibacter subterraneus 302 biofilms grown on graphite planar electrodes. A) Maximum intensity projection and B) 303 Orthogonal cross section of a single slice through the biofilm with top and right panels 304 representing perpendicular slices.

305 306

\subsubsection{Proof that the presence of an electroactive biofilm is due to metabolically active}

\section{bacterial cells transferring electrons to the electrode}

To support that the biofilm formation was due to the electrons harvested from the substrate oxidation followed by a later release to the electrode surface by the electroactive biofilm, CLSM images were compared to a non-electrochemical negative control. This control was an electrode placed in the same electrochemical cell of a Glk. subterraneus electrochemical experiment but not potentiostatically controlled (i.e., the electrode was immersed in the same growth medium during the electrochemical biofilm growth). The result of such CLSM observations is shown in Fig. S8 and Table S3. When comparing CLSM pictures in Fig. S8, the difference between both maximum intensity projections and orthogonal cross sections is very clear. While for the potentiostatically controlled electrode there was an evident thick biofilm formed of metabolically active bacteria, for the negative control no significant coverage of the electrode surface and biofilm formation was observed (see Table S3). These findings are consistent with the observations made by Malvankar et al. (2011) ${ }^{66}$. They utilized in a similar way a non-connected electrode as negative control electrode. The values of electrode coverage and thickness calculated here for the negative control electrode suggest that the bacterial cells stained with the LIVE/DEAD kit corresponded to a heterogenous deposition of bacterial cells likely de-attached from the potentiostatically controlled electrode in which Glk. subterraneus was forming an electroactive biofilm (Fig. S8).

These CLSM findings are well in line with previous studies of ARB able to produce high currents and thick biofilms such as Geobacter sulfurreducens ${ }^{15,17,29,51,66}$ and Thermincola ferriacetica $^{22}$ but in clear contrast to other low current producing bacteria like Shewanella species $^{19}$. On the other side, similar observations of biofilm coverage of an electrode material were obtained with Scanning electron microscopy measurements in Rhodopseudomonas palustris DX-1 ${ }^{40}$, Geoalkalibacter ferrihydriticus ${ }^{30}$ and Geolkalibacter subterraneus ${ }^{30}$. 


\section{Conclusions}

332 The present study on the characterization of Geoalkalibacter subterraneus is summarized in 333 Fig. 5 and indicates the following findings: CA exhibited the highest current density (4.68 \pm $3340.54 \mathrm{~A} / \mathrm{m}^{2}$ ) produced on a planar electrode for a pure culture of an ARB under saline 335 conditions $(3.5 \% \mathrm{NaCl}) . \mathrm{CV}$ under turnover and non-turnover conditions made evident the 336 appearance of two different redox couples for each condition. When comparing their formal 337 potentials, two of them had a very close value $\left(E_{\mathrm{f}, 2}\right.$ and $\left.E_{\mathrm{f}, 3}\right)$ indicating that the molecule (or 338 molecules) responsible for the ET mechanism might fall between the potential window 339 delimited by $E_{\mathrm{f}, 2}$ and $E_{\mathrm{f}, 3}$. CLSM confirmed a biofilm composed of several layers of 340 metabolically active bacteria that spread all over the electrode material with a thick biofilm up 341 to $76 \pm 7 \mu \mathrm{m}$ height but a low electrode coverage of only $23 \pm 7 \%$. From these findings, it is 342 then proposed that Geoalkalibacter subterraneus performs a DET mechanism in contact with 343 the electrode material. Nevertheless, to firmly determine the molecule responsible for the ET 344 mechanism future work will be performed by employing Surface Enhanced Resonance 345 Raman Spectroscopy, a technique successfully used to detect selectively cellular membrane 346 redox proteins in proximity of the electrode surface ${ }^{63,67,68}$. 


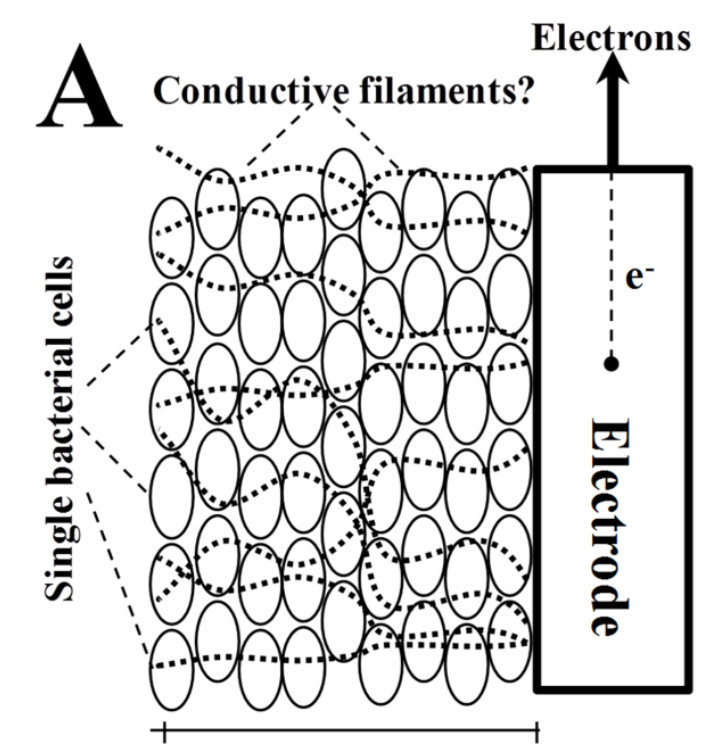

Biofilm thickness :76 $\mu \mathrm{m}$

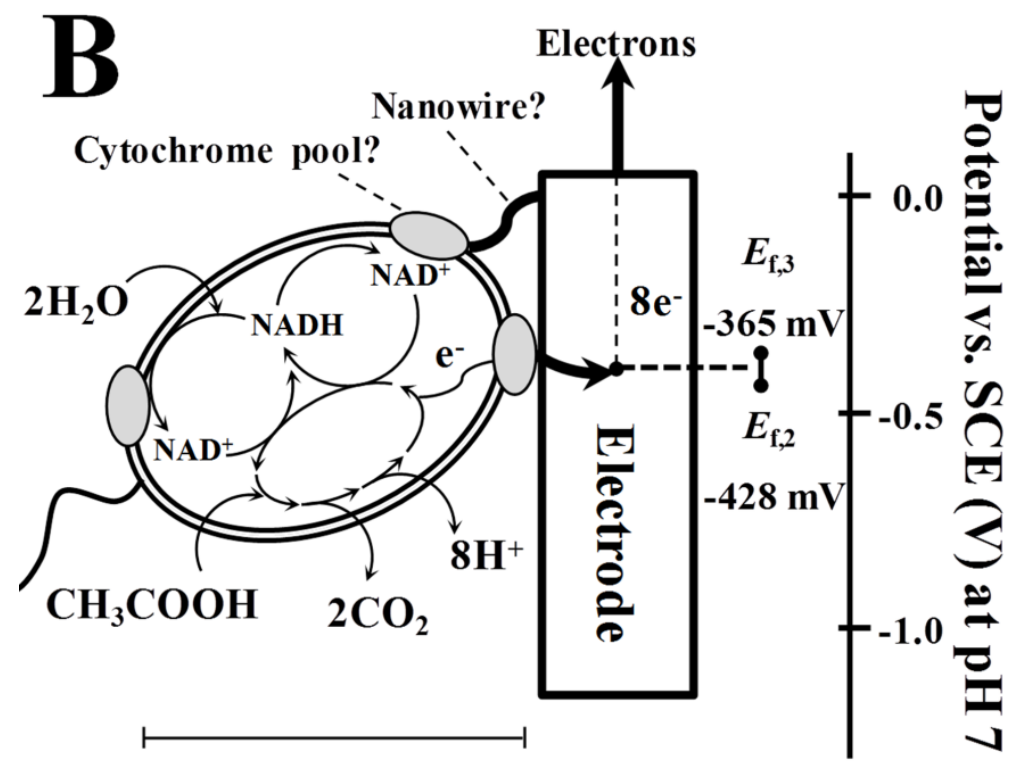

Geoalkalibacter subterraneus cell (5-6 $\mu \mathrm{m})$

348 Fig. 5 Conceptual illustration of the DET mechanism performed by Geoalkalibacter 349 subterraneus derived from the electrochemical and microscopic characterization 350 accomplished here. A) Representation of the visible apparent biofilm with a 70-80 $\mu$ m 351 thickness that could possibly contain conductive filaments ${ }^{30}$ to transport electrons by the so 352 called long-range $\mathrm{ET}^{69}$ through the biofilm composed of monolayers of stained green cells as

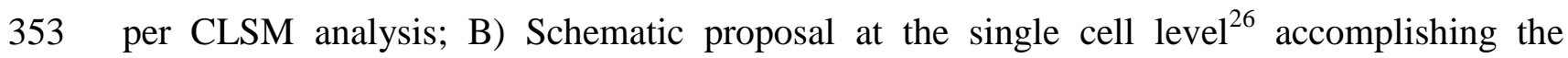
354 oxidation of acetate to produce carbon dioxide and harvest of electrons, for instance, by the 355 tricarboxylic acid cycle ${ }^{70}$ to perform a DET mechanism via a putative cytochrome (or 356 cytochrome pool) with a formal potential "conduit" $\left(E_{\mathrm{f}}\right)$ between -428 and $-365 \mathrm{mV}$ vs. SCE 357 determined during CV analysis. 


\subsection{General conditions}

360 All chemicals were of analytical or biochemical grade and were purchased from Sigma361 Aldrich and Merck. If not stated otherwise, all potentials provided in this manuscript refer to 362 the SCE reference electrode $(\mathrm{KCl} 3.0 \mathrm{M},+240 \mathrm{mV}$ vs. SHE, Materials Mates, La Guilletière 36338700 Sarcenas, France). All media preparations were adjusted to $\mathrm{pH} 7$, vigorously flushed 364 with $\mathrm{N}_{2}$ gas (purity $\geq 99.9999$, Linde France S.A.) for at least $30 \mathrm{~min}$ using a commercial air 365 stone (or aquarium bubbler) and then autoclaved $\left(121^{\circ} \mathrm{C}\right.$ for $20 \mathrm{~min}$ ). Bioelectrochemical 366 experiments were conducted under potentiostatic control and strictly anoxic ${ }^{71,72}$ and sterile conditions. All incubations were performed at $37^{\circ} \mathrm{C}$.

\subsection{Metabolite and biogas analysis}

Acetate consumption was determined by liquid injection into a gas chromatograph (GC 8000, Fisons Instruments) according to Aceves-Lara et al., $2008^{73}$. Biogas composition $\left(\mathrm{CH}_{4}, \mathrm{CO}_{2}\right.$, $\mathrm{H}_{2}$ and $\mathrm{N}_{2}$ ) was determined using a gas chromatograph (Clarus 580, Perkin Elmer) coupled to Thermal Catharometric detection, as described elsewhere ${ }^{74}$.

\section{3}

374

375

\subsection{Cell cultures and media}

Geoalkalibacter subterraneus strain Red1 was purchased from DSMZ (DSM No.: 23483, German Collection of Microorganisms and Cell Cultures GmbH, Braunschweig, Germany). Sterile growth medium $\mathrm{FRR}^{26}$ was used for routinely culture maintenance and contained (per L): $17.0 \mathrm{~g}$ of NaCl, $4.50 \mathrm{~g}$ of $\mathrm{MgCl}_{2} \cdot 6 \mathrm{H}_{2} \mathrm{O}, 0.35 \mathrm{~g}$ of $\mathrm{CaCl}_{2} \cdot 2 \mathrm{H}_{2} \mathrm{O}, 1.00 \mathrm{~g}$ of $\mathrm{NH}_{4} \mathrm{Cl}, 0.08 \mathrm{~g}$ $\mathrm{KH}_{2} \mathrm{PO}_{4}, 3.50 \mathrm{~g}$ of $\mathrm{NaHCO}_{3}, 3.00 \mathrm{~g}$ of Yeast extract, $1 \mathrm{~mL}$ of trace element solution, $1 \mathrm{~mL}$ of selenite-tungstate solution, $2.55 \mathrm{~g}$ of $\mathrm{NaNO}_{3}$ as final electron acceptor when Glk. subterraneus cells were harvested for further growth in electrochemical cells (as described below) and $1.00 \mathrm{~g}$ of $\mathrm{CH}_{3} \mathrm{COONa}$ as electron donor.

As stated before, the novel ARB Glk. subterraneus was the bacterium dominating high current producing biofilms in previous studies of our group ${ }^{31}$. Therefore, for the growth of Glk. subterraneus biofilms on graphite electrodes (i.e., in electrochemical experiments) two similar media compositions were used. Medium $\mathrm{FRR}^{26}$ without $\mathrm{NaNO}_{3}$ and modified Starkey medium as reported elsewhere ${ }^{75}$ were used. The later was used previously for the selection and identification of Glk. subterraneus in a potentiostically controlled $\mathrm{BES}^{31}$. Starkey medium contained per liter: $35.0 \mathrm{~g} \mathrm{NaCl}, 0.5 \mathrm{~g} \mathrm{~K}_{2} \mathrm{HPO}_{4}, 2.0 \mathrm{~g} \mathrm{NH} 4 \mathrm{Cl}, 7.6 \mathrm{~g}$ MES buffer, $0.2 \mathrm{~g}$ Yeast Extract, $1 \mathrm{~mL}$ of oligo-elements solution and $10 \mathrm{mM}$ sodium acetate as electron donor. Oligoelements solution contained (per L): $46 \mathrm{~mL} \mathrm{HCl} 37 \%, 55 \mathrm{~g} \mathrm{MgCl}_{2} \cdot 6 \mathrm{H}_{2} \mathrm{O}, 7.0 \mathrm{~g}$ 
$\mathrm{FeSO}_{4}\left(\mathrm{NH}_{4}\right)_{2} \mathrm{SO}_{4} \cdot 6 \mathrm{H}_{2} \mathrm{O}, 1.0 \mathrm{~g} \mathrm{ZnCl}_{2} \cdot 2 \mathrm{H}_{2} \mathrm{O}, 1.2 \mathrm{~g} \mathrm{MnCl}_{2} \cdot 4 \mathrm{H}_{2} \mathrm{O}, 0.4 \mathrm{~g} \mathrm{CuSO}_{4} \cdot 5 \mathrm{H}_{2} \mathrm{O}, 1.3 \mathrm{~g}$

$392 \mathrm{CoSO}_{4} \cdot 7 \mathrm{H}_{2} \mathrm{O}, 0.1 \mathrm{~g}^{\mathrm{B}} \mathrm{BO}_{3} \mathrm{H}_{3}, 1.0 \mathrm{~g} \quad \mathrm{Mo}_{7} \mathrm{O}_{24}\left(\mathrm{NH}_{4}\right)_{6} \cdot 4 \mathrm{H}_{2} \mathrm{O}, 0.05 \mathrm{~g} \mathrm{NiCl}_{2} \cdot 6 \mathrm{H}_{2} \mathrm{O}, 0.01 \mathrm{~g}$

$393 \mathrm{Na}_{2} \mathrm{SeO}_{3} \cdot 5 \mathrm{H}_{2} \mathrm{O}$ and $60.0 \mathrm{~g} \mathrm{CaCl}_{2} \cdot 2 \mathrm{H}_{2} \mathrm{O}$. The examination of the two media in electrochemical 394 experiments inoculated with Glk. subterraneus led to similar performance (see Fig.S1 and 395 Table S2).

396 As stated before, to conduct an accurate comparison of the performance obtained with Glk. 397 subterraneus, parallel electrochemical experiments were carried out with Gb. sulfurreducens 398 (DSM strain number 12127). Gb. sulfurreducens cells were harvested for electrochemical 399 experiments as reported elsewhere ${ }^{28,60,76}$, except during growth on graphite electrodes. In 400 experiments reported here with Gb. sulfurreducens, no gas was flushed during the growth of 401 biofilms in electrochemical experiments.

\section{$402 \quad 4.4$ Electrode preparation}

403 Preparation of electrodes was according to the procedure reported elsewhere ${ }^{77}$. In brief: 404 working electrodes were $2.5 \mathrm{~cm} \times 2.5 \mathrm{~cm} \times 0.25 \mathrm{~cm}$ (total immersed projected electrode 405 surface area of $15 \mathrm{~cm}^{2}$ ) planar graphite plates (C000440/15, Goodfellow SARL, 229 Rue 406 Solférino, F-59000 Lille, France) screwed onto $2 \mathrm{~mm}$ diameter, $15 \mathrm{~cm}$ long titanium rods 407 (TI007910/13, Goodfellow) that ensured electrical connection. Planar graphite electrodes 408 were used as delivered by the provider. Counter electrodes were 90\% Platinum-10\% Iridium 409 grids joint by heating in a blue flame with a $0.5 \mathrm{~mm}$ diameter, $15 \mathrm{~cm}$ long $90 \%$ Platinum-10\% 410 Iridium rod (Heraeus PSP S.A.S., Contact Materials Division, 526, Route des Gorges du 411 Sierroz, 73100 Grésy-sur-Aix France).

\section{$412 \quad 4.5$ Bioelectrochemical set-up and experiments}

413 Glk. subterraneus and Gb. sulfurreducens biofilms were grown in potentiostatically 414 controlled half-cells (autoclavable borosilicate glass) containing $500 \mathrm{~mL}$ of solution with 415 around $200 \mathrm{~mL}$ of headspace as reported elsewhere ${ }^{77}$. The lid and the reactor body were 416 sealed with a clamping ring. Biofilm growth was performed in semi-batch 417 chronoamperometric (CA) experiments with media replacement as described previously ${ }^{19}$ at a 418 fixed applied potential of $+200 \mathrm{mV}$ using a Potentiostat/Galvanostat VMP3 (BioLogic 419 Science Instruments, France). After half-cells containing electrodes were completely 420 assembled (i.e., before inoculation of bacterial cells) anoxic conditions were assured similarly 421 as in previous reports ${ }^{28,60,76}$. Here, we flushed the media with high purity $\mathrm{N}_{2}(\geq 99.9999 \%)$ 422 for at least $30 \mathrm{~min}$. The final composition of the gas phase was typically a mixture of $\mathrm{O}_{2}: 1.41$ 423 $\pm 1.16 \%$ and $\mathrm{N}_{2}: 98.56 \pm 1.18 \%$. 
424 Inoculation of bacterial cells was carried out as previously described ${ }^{19}$. Concisely, $50 \mathrm{~mL}$ of 425 media in the early stationary phase (i.e., $\mathrm{OD}^{620}$ approx. 0.3-0.4) were anoxically sampled ${ }^{71,72}$ 426 and centrifuged at $3000 \mathrm{rpm}$ for $10 \mathrm{~min}$. The pellet was re-suspended in $10 \mathrm{~mL}$ of the 427 respective media for electrochemical experiments and injected in the electrochemical cell (see 428 Fig. S9).

\section{4.6 Cyclic voltammetry (CV) for an insight into the electron transfer (ET) mechanism}

430 Different types of CVs were recorded during experiments according to Refs. ${ }^{19,27,78}$ (see Fig.

431 1). Control $\mathrm{CV}$ of the bare graphite electrode immersed in growth media before starting $\mathrm{CA}$ 432 and inoculating the half-cell (dotted line in Fig. 2A), turnover CV of a Glk. subterraneus 433 biofilm, i.e. at bioelectrocatalytic substrate consumption (continuous line in Fig. 2A) and two 434 types of non-turnover CV of a Glk. subterraneus biofilm: during substrate depleted conditions 435 (continuous line in Fig. 3A) and during substrate deprived conditions (continuous line in Fig. 436 3B).

\section{$437 \quad 4.7$ Data processing}

438 CA maximum current densities $\left(j_{\max }\right)$ of established microbial biofilms were analyzed considering the total immersed electrode surface area since electroactive biofilms covered both sides of the working electrode as per our observations (i.e., not only the side of graphite working electrode facing Pt-Ir counter electrode, see Fig. S5). Here all data are based on experiments of at least two independent biofilm replicates ${ }^{79}$ and standard deviations are presented through all the manuscript. For in-depth data analyses of $\mathrm{CV}$, the open-source software SOAS ${ }^{62}$ was used for baseline (capacitive current) correction for non-turnover 445 conditions.

\subsection{Confocal laser scanning microscopy (CLSM) to measure biofilm electrode coverage} and thickness

Glk. subterraneus biofilms (and Gb. sulfurreducens for comparison) grown on planar graphite plate electrodes were examined by CLSM after staining with nucleic acid-specific fluorochromes. For this purpose, whole electrodes were mounted on a plastic petri dish and subsequently stained with the LIVE/DEAD ${ }^{\circledR}$ BacLight $^{\mathrm{TM}}$ Bacterial Viability Kit (Invitrogen) as proposed by the manufacturer. Stained biofilms were covered with tap water and confocal images of electroactive biofilms were acquired with a confocal laser scanning system (Leica TCS SP2, Leica Microsystems, Wetzlar, Germany) using a 40x water immersion objective 455 (numerical aperture 0.8). Biofilms were observed with the $488 \mathrm{~nm}$ ray line of an argon laser 456 for excitation and the emitted light was collected in the 495- $616 \mathrm{~nm}$ spectral range. The 
457 system was controlled by the Leica LCS software (version 2.61) (Leica, Germany). Each 458 electroactive biofilm attached to the electrode was scanned for CLSM images at three 459 different random locations; therefore, CLSM images were representative of the entire 460 electrode. These images were qualitatively inspected (LAS AF 2.4.1 build 6384, Leica 461 Microsystems and Volocity ${ }^{\circledR}$ Demo Version $6.2 .1^{80}$, PerkinElmer). Images were later 462 thresholded at $60^{81}$ and quantitatively analyzed with PHobia Laser scanning microscopy 463 Imaging Processor 0.3 (PHLIP) ${ }^{82}$, an open source public license Matlab toolbox commonly 464 used for the analysis of electroactive biofilms ${ }^{15,65,66}$.

\section{Acknowledgments}

466 This research was financed by the French National Research Agency (ANR-09-BioE-10 467 DéfiH12). The authors gratefully acknowledge C. Pouzet and A. Le Ru for technical 468 assistance with CLSM. A.A.C.M thanks E. Latrille, V. Rossard and L. Dantas for help with 469 Matlab/PHLIP and Linux/SOAS software handling and C. Rivalland for critical reading of the 470 manuscript. 
473 1. S. Patil, C. Hägerhäll and L. Gorton, Bioanal. Rev., 2012, 4, 159-192.

$474 \quad 2 . \quad$ B. E. Logan, B. Hamelers, R. Rozendal, U. Schröder, J. Keller, S. Freguia, P. Aelterman, W.

3. B. E. Logan, D. Call, S. Cheng, H. V. M. Hamelers, T. H. J. A. Sleutels, A. W. Jeremiasse and R. A. Rozendal, Environ. Sci. Technol., 2008, 42, 8630-8640.

4. $\quad$ K. Rabaey and R. A. Rozendal, Nat. Rev. Micro., 2010, 8, 706-716.

5. D. R. Lovley, Energy Environ. Sci., 2011, 4, 4896-4906.

6. A. A. Carmona-Martínez, F. Harnisch, L. A. Fitzgerald, J. C. Biffinger, B. R. Ringeisen and U. Schröder, Bioelectrochemistry, 2011, 81, 74-80.

7. K. Rabaey, N. Boon, M. Höfte and W. Verstraete, Environ. Sci. Technol., 2005, 39, 34013408 .

8. E. Marsili and X. Zhang, in Bioelectrochemical Systems: from Extracellular Electron Transfer to Biotechnological Application, eds. K. Rabaey, L. Angenent, U. Schroder and J. Keller, 2010, pp. 59-80.

9. M. E. Hernandez and D. K. Newman, Cell. Mol. Life Sci., 2001, 58, 1562-1571.

10. U. Schröder, Phys. Chem. Chem. Phys., 2007, 9, 2619-2629.

11. K. Watanabe, M. Manefield, M. Lee and A. Kouzuma, Curr. Opin. Biotechnol., 2009, 20, 633-641.

12. K. P. Katuri, S. Rengaraj, P. Kavanagh, V. O'Flaherty and D. Leech, Langmuir, 2012, 28, 7904-7913.

13. G. Reguera, K. P. Nevin, J. S. Nicoll, S. F. Covalla, T. L. Woodard and D. R. Lovley, Appl. Environ. Microbiol., 2006, 72, 7345-7348.

14. A. E. Franks, R. H. Glaven and D. R. Lovley, ChemSusChem, 5, 1092-1098.

15. A. E. Franks, K. P. Nevin, H. Jia, M. Izallalen, T. L. Woodard and D. R. Lovley, Energy Environ. Sci., 2009, 2, 113-119.

16. A. E. Franks, K. P. Nevin, R. H. Glaven and D. R. Lovley, ISME J, 2010, 4, 509-519.

17. K. P. Nevin, H. Richter, S. F. Covalla, J. P. Johnson, T. L. Woodard, A. L. Orloff, H. Jia, M. Zhang and D. R. Lovley, Environ. Microbiol., 2008, 10, 2505-2514.

18. K. P. Nevin, B.-C. Kim, R. H. Glaven, J. P. Johnson, T. L. Woodard, B. A. Methé, R. J. DiDonato, Jr., S. F. Covalla, A. E. Franks, A. Liu and D. R. Lovley, PLoS ONE, 2009, 4, e5628.

19. A. A. Carmona-Martínez, F. Harnisch, U. Kuhlicke, T. R. Neu and U. Schröder, Bioelectrochemistry, 2012.

20. A. Okamoto, R. Nakamura and K. Hashimoto, Electrochim. Acta, 2011, 56, 5526-5531.

21. A. Jain, X. Zhang, G. Pastorella, J. O. Connolly, N. Barry, R. Woolley, S. Krishnamurthy and E. Marsili, Bioelectrochemistry, 2013, 87, 28-32.

22. P. Parameswaran, T. Bry, S. Popat, B. G. Lusk, B. E. Rittmann and C. I. Torres, Environ. Sci. Technol., 2013. 47, 4934-4940.

23. C. I. Torres, A. K. Marcus, H. S. Lee, P. Parameswaran, R. Krajmalnik-Brown and B. E. Rittmann, FEMS Microbiol. Rev., 2010, 34, 3-17.

24. F. Harnisch and K. Rabaey, ChemSusChem, 2012, 5, 1027-1038.

25. M. Pierra, Commun. Agric. Appl. Biol. Sci., 2012, 77, 58.

26. A. C. Greene, B. K. C. Patel and S. Yacob, Int. J. Syst. Evol. Microbiol., 2009, 59, 781-785.

27. K. Fricke, F. Harnisch and U. Schroder, Energy Environ. Sci., 2008, 1, 144-147.

28. C. Dumas, R. g. Basseguy and A. Bergel, Electrochim. Acta, 2008, 53, 3200-3209.

29. H. Richter, K. McCarthy, K. P. Nevin, J. P. Johnson, V. M. Rotello and D. R. Lovley, Langmuir, 2008, 24, 4376-4379.

30. J. P. Badalamenti, R. Krajmalnik-Brown and C. I. Torres, mBio, 2013, 4.

31. M. Pierra, E. Trably, J.-J. Godon and N. Bernet, unpublished work.

32. J. F. Miceli, P. Parameswaran, D.-W. Kang, R. Krajmalnik-Brown and C. I. Torres, Environ. Sci. Technol., 2012, 46, 10349-10355.

33. O. Lefebvre, Z. Tan, S. Kharkwal and H. Y. Ng, Bioresour. Technol., 2012, 112, 336-340.

34. S. Cheng, H. Liu and B. E. Logan, Environ. Sci. Technol., 2006, 40, 2426-2432.

35. H. Liu, R. Ramnarayanan and B. E. Logan, Environ. Sci. Technol., 2004, 38, 2281-2285. 
36. H. Liu, S. Cheng and B. E. Logan, Environ. Sci. Technol., 2005, 39, 658-662.

37. E. Lalaurette, S. Thammannagowda, A. Mohagheghi, P.-C. Maness and B. E. Logan, Int. J. Hydrogen Energy, 2009, 34, 6201-6210.

38. D. R. Bond and D. R. Lovley, Appl. Environ. Microbiol., 2003, 69, 1548-1555.

39. L. Zhu, H. Chen, L. Huang, J. Cai and Z. Xu, Eng. Life Sci., 2011, 11, 238-244.

40. D. Xing, Y. Zuo, S. Cheng, J. M. Regan and B. E. Logan, Environ. Sci. Technol., 2008, 42, 4146-4151.

41. C. W. Marshall and H. D. May, Energy Environ. Sci., 2009, 2, 699-705.

535

S. Xu and H. Liu, J. Appl. Microbiology, 2011, 111, 1108-1115.

D. Xing, S. Cheng, B. Logan and J. Regan, Appl. Microbiol. Biotechnol., 2010, 85, 15751587.

48. T. Zhang, L. Zhang, W. Su, P. Gao, D. Li, X. He and Y. Zhang, Bioresour. Technol., 2011, 102, 7099-7102.

49. Y. Yuan, J. Ahmed, L. Zhou, B. Zhao and S. Kim, Biosens. Bioelectron., 2011, 27, 106-112.

50. D. E. Holmes, D. R. Bond and D. R. Lovley, Appl. Environ. Microbiol., 2004, 70, 1234-1237.

51. A. Jain, G. Gazzola, A. Panzera, M. Zanoni and E. Marsili, Electrochim. Acta, 2011, 56, 10776-10785.

52. J. Niessen, U. Schröder, F. Harnisch and F. Scholz, Lett. Appl. Microbiol., 2005, 41, 286-290.

53. X. Zhu, M. D. Yates and B. E. Logan, Electrochem. Commun., 2012, 22, 116-119.

54. S. M. Strycharz, A. P. Malanoski, R. M. Snider, H. Yi, D. R. Lovley and L. M. Tender, Energy Environ. Sci., 2011, 4, 896-913.

55. K. P. Katuri, P. Kavanagh, S. Rengaraj and D. Leech, Chem. Commun., 2010, 46, 4758-4760.

56. J. Wei, P. Liang, X. Cao and X. Huang, Environ. Sci. Technol., 2010, 44, 3187-3191.

57. E. Marsili, J. Sun and D. R. Bond, Electroanalysis, 2010, 22, 865-874.

58. H. Richter, K. P. Nevin, H. Jia, D. A. Lowy, D. R. Lovley and L. M. Tender, Energy Environ. Sci. 2009, 2, 506-516.

59. S. Srikanth, E. Marsili, M. C. Flickinger and D. R. Bond, Biotechnol. Bioeng., 2008, 99, $1065-$ 1073.

60. C. Dumas, R. Basseguy and A. Bergel, Electrochim. Acta, 2008, 53, 2494-2500.

61. E. Marsili, J. B. Rollefson, D. B. Baron, R. M. Hozalski and D. R. Bond, Appl. Environ. Microbiol., 2008, 74, 7329-7337.

62. V. Fourmond, K. Hoke, H. A. Heering, C. Baffert, F. Leroux, P. Bertrand and C. Léger, Bioelectrochemistry, 2009, 76, 141-147.

63. D. Millo, F. Harnisch, S. A. Patil, H. K. Ly, U. Schröder and P. Hildebrandt, Angew. Chem., Int. Ed., 2011, 50, 2625-2627.

64. A. E. Franks, N. Malvankar and K. P. Nevin, Biofuels, 2010, 1, 589-604.

65. L. V. Richter, S. J. Sandler and R. M. Weis, J. Bacteriol., 2012, 194, 2551-2563.

66. N. S. Malvankar, M. Vargas, K. P. Nevin, A. E. Franks, C. Leang, B.-C. Kim, K. Inoue, T. Mester, S. F. Covalla, J. P. Johnson, V. M. Rotello, M. T. Tuominen and D. R. Lovley, Nat. Nanotechnol., 2011, 6, 573-579.

67. H. K. Ly, F. Harnisch, S.-F. Hong, U. Schröder, P. Hildebrandt and D. Millo, ChemSusChem, 2013, 6, 487-492.

68. D. Millo, Bioanal. Rev., 2012, 40, 1284-1290.

69. N. S. Malvankar and D. R. Lovley, ChemSusChem, 2012, 5, 1039-1046.

70. D. R. Lovley, Nat Rev Micro, 2006, 4, 497-508.

71. T. L. Miller and M. J. Wolin, J. Appl. Microbiol., 1974, 27, 985-987.

72. R. E. Hungate and J. Macy, Bulletins from the Ecological Research Committee, 1973, 123126.

73. C. s. A. Aceves-Lara, E. Latrille, P. Buffiere, N. Bernet and J.-P. Steyer, Chem. Eng. Process. Process Intensif., 2008, 47, 1968-1975.

74. M. Quéméneur, J. Hamelin, A. Barakat, J.-P. Steyer, H. Carrère and E. Trably, Int. J. Hydrogen Energy, 2012, 37, 3150-3159. 
75. Y. Rafrafi, E. Trably, J. Hamelin, E. Latrille, I. Meynial-Salles, S. Benomar, M.-T. GiudiciOrticoni and J.-P. Steyer, Int. J. Hydrogen Energy, 2013.

76. C. Dumas, R. g. Basseguy and A. Bergel, Electrochim. Acta, 2008, 53, 5235-5241.

77. S. F. Ketep, A. Bergel, M. Bertrand, W. Achouak and E. Fourest, Bioresour. Technol., 2013, 127, 448-455.

78. F. Harnisch and S. Freguia, Chem. Asian J., 2012, 7, 466-475.

79. B. E. Logan, ChemSusChem, 2012, 5, 988-994.

80. S. Beaufort, S. Alfenore and C. Lafforgue, J. Membr. Sci., 2011, 369, 30-39.

81. X. Yang, H. Beyenal, G. Harkin and Z. Lewandowski, Water Res., 2001, 35, 1149-1158.

82. L. Mueller, J. de Brouwer, J. Almeida, L. Stal and J. Xavier, BMC Ecology, 2006, 6, 1. 